\title{
Preparation of Microcapsules Containing Camellia Oil with Heterocoagulation between Chitosan and Oleic Acid
}

\author{
Natsukaze Saito, Yoshinari Taguchi, Masato Tanaka* \\ Graduate School of Science and Technology, Niigata University, Niigata, Japan \\ Email: *tanaka@eng.niigta-u.ac.jp
}

How to cite this paper: Saito, N., Taguchi, Y. and Tanaka, M. (2018) Preparation of Microcapsules Containing Camellia Oil with Heterocoagulation between Chitosan and Oleic Acid. Journal of Cosmetics, Dermatological Sciences and Applications, 8, 14-24.

https://doi.org/10.4236/jcdsa.2018.81004

Received: February 2, 2018

Accepted: March 10, 2018

Published: March 13, 2018

Copyright $\odot 2018$ by authors and Scientific Research Publishing Inc. This work is licensed under the Creative Commons Attribution International License (CC BY 4.0).

http://creativecommons.org/licenses/by/4.0/

\begin{abstract}
It was tried to microencapsulate camellia oil using heterocoagulation between fatty acid dissolved in camellia oil and chitosan dissolved in the continuous water phase. Oleic acid as a fatty acid was dissolved in camellia oil in order to certainly form the microcapsule shell made from oleic acid and chitosan. The microcapsules were observed with optical microscope and characterized about the diameters, $\zeta$-potential, FTIR analysis and adhesion feature on human hair. Microcapsules with the mean diameter in the range from ca. $1.5 \mu \mathrm{m}$ to $4.5 \mu \mathrm{m}$ could be prepared with the preparation method presented in this study. The oil droplets of camellia oil charged negatively to be $-54.6 \mathrm{mV}$ and the microcapsules charged positively to be $59.6 \mathrm{mV}$. The microcapsules adhered well on the negatively charged human hair and were kept stably before and after drying at room temperature for $24 \mathrm{~h}$ and blowing.
\end{abstract}

\section{Keywords}

Microencapsulation, Camellia Oil, Heterocoagulation, Hair Dressing Material, Fatty Acid

\section{Introduction}

As the microcapsules can contain the core materials such as gas, liquid and solid and have the various functions, until now a deal of microcapsules have been prepared and applied in the various fields such as cosmetics, foods, drugs, textiles, electric materials, latent heat storage, paintings and adhesives [1] [2] [3].

The main important functions of microcapsules are to protect the core materials from environment for a long time, to optionally release the core materials according to stimuli such as mechanical pressure, heat and $\mathrm{pH}$ of solvent, to 
modify the surface of core materials and to change the core materials such as liquid and gas to the fine solid particles [1] [2] [3]. The microcapsules with these functions can be prepared with the physicochemical methods such as the coacervation method, the drying in liquid method, the spray dried method, the heterocoagulation method and the chemical methods such as the suspension polymerization method, the interfacial polymerization method, the mini emulsion polymerization method, the gelling in liquid method and the in-situ polymerization method [1] [2] [3].

Recently, many works about the microencapsulation of essential oils have been reported [4]-[10]. For example, many kinds of oil species have been microencapsulated with the interfacial gelling reaction method [11] [12] [13], the in-situ polymerization method [14] [15], the interfacial polycondensation reaction method [16] [17], the coacervation method [18] [19], the spray-dried method [20] [21] [22] and the melting dispersion cooling method [23]. These microcapsules have been applied to the textiles, fragrance, aromatherapy, antibiosis and so on.

In Japan, camellia oil which was produced from camellia tea seed was rich in oleic acid and has been said to be good for hair.

So, it is well known that camellia oil has been used from long ago as the hair dressing material and the face treatment material in the cosmetic field [24]. Here, if the microcapsules are going to be applied in the cosmetic field, it is very important to microencapsulate camellia oil with biocompatible materials. Furthermore, if camellia oil could be microencapsulated with harmless materials and broken with the hand pressure, the soft microcapsules like the microencapsulated camellia oil may be positively recommended as a hair dressing material, because camellia oil can be retained stably and prevented from oxidation.

Taking these things into consideration, the fundamental experiment about microencapsulation of camellia oil with chitosan was conducted using the heterocoagulation method.

The purposes of this study are to investigate whether camellia oil could be microencapsulated with chitosan on the basis of heterocoagulation or not and to characterize whether the microencapsulated camellia oil could be applied as the hair dressing material or not.

\section{Experimental}

\subsection{Materials}

Materials used to prepare the microcapsules were as follows. Camellia oil (CO: Oshima Tsubaki Co. Ltd., Japan) was microencapsulated as a core material. Oleic acid (OA: Wako Pure Chemicals Co., Ltd., Tokyo, Japan) was dissolved into camellia oil in order to stably form the microcapsule shell regardless of fluctuation of components in natural camellia oil.

Chitosan (Wako Pure Chemicals Co., Ltd., Tokyo, Japan) was used to form the microcapsule shell using heterocoagulation with oleic acid. Citric acid (Wa- 
ko Pure Chemicals Co., Ltd., Tokyo, Japan) was used to dissolve chitosan in the water phase. Soybean lecithin (SBL: Wako Pure Chemicals Co., Ltd., Tokyo, Japan) was used as an oil soluble surfactant.

\subsection{Preparation of Microcapsules}

Figure 1 shows the flow sheet for preparing the microcapsules.

Camellia oil (CO) and Oleic acid (OA) of given volume were mixed together to form the oil dispersed phase $(\mathrm{O})$, in which soybean lecithin (SBL) was dissolved beforehand.

The oil dispersed phase was added into the continuous water phase (W) and stirred with the rotor stator homogenizer to form the $(\mathrm{O} / \mathrm{W})$ emulsion.

Then, the chitosan aqueous solution of a given concentration was added to the $(\mathrm{O} / \mathrm{W})$ emulsion. The $(\mathrm{O} / \mathrm{W})$ emulsion was stirred with the impeller for a given time $(\mathrm{ca} .4 \mathrm{~h}$ ) to form the microcapsules. The fundamental operation described above was performed changing mainly the revolution velocity to form the $(\mathrm{O} / \mathrm{W})$ emulsion. The microcapsules prepared thus were collected with filtration paper and characterized. The experimental conditions are shown in Table 1.

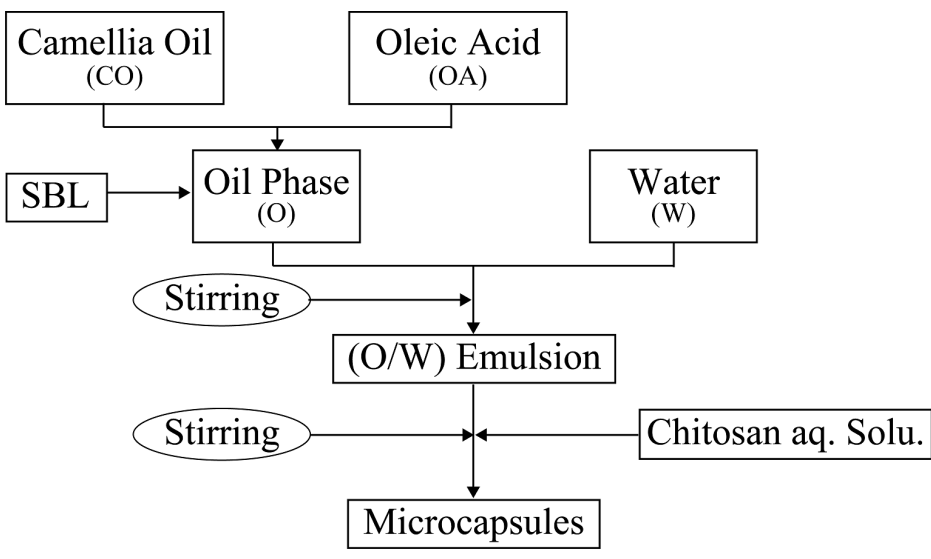

Figure 1. Flow sheet for preparing microcapsules.

Table 1. Experimental conditions.

\begin{tabular}{cccc}
\hline & Oil Phase & Formation of (O/W) Emulsion \\
\hline Camellia Oil & $2.0 \mathrm{~g}$ & $\mathrm{Nr}$ & $2000-10,000 \mathrm{rpm}$ \\
Oleic Acid & $0.2 \mathrm{~g}(10 \mathrm{wt} \%$-Oil $)$ & $\mathrm{t}$ & $5 \mathrm{~min}$ \\
& Continuous Phase & $\mathrm{T}$ & $40^{\circ} \mathrm{C}$ \\
Water & $300 \mathrm{~g}$ & Microencapsulation Process \\
\hline \multicolumn{2}{c}{ Chitosan aq. Solution } & $\mathrm{Nr}$ & $60 \mathrm{rpm}$ \\
Chitosan & $0.2 \mathrm{~g}(1.0 \mathrm{wt} \%$-Water $)$ & $\mathrm{t}$ & $4 \mathrm{~h}$ \\
Water & $20 \mathrm{~g}$ & $\mathrm{~T}$ & $40^{\circ} \mathrm{C}$ \\
Citric Acid & $0.2 \mathrm{~g}(1.0 \mathrm{wt} \%$-Water $)$ &
\end{tabular}




\subsection{Characterization}

\subsubsection{Diameter Distribution and Mean Diameter}

The diameter distributions and the mean diameters of the oil droplets and the microcapsules were measured by Particle Size Analyzer (SALD-3000, Shimazu Seisakusho, Ind., Co., Ltd., Kyoto, Japan). Here, the mean diameters were the Sauter mean diameters.

\subsection{2. $\zeta$-Potential}

The $\zeta$-potentials of the oil droplets in the $(\mathrm{O} / \mathrm{W})$ emulsion and the microcapsules dispersed in the continuous water phase were measured with Particle Size Analyzer (ELSE-2: Otsuka Electronics, Co., Ltd., Tokyo).

\subsubsection{Observation of Emulsion and Microcapsules}

The $(\mathrm{O} / \mathrm{W})$ emulsion and the microcapsules were observed by stereo optical microscope (BH-2VMA: Olympus, Co., Ltd., Tokyo, Japan). From these photographs, the stability of the $(\mathrm{O} / \mathrm{W})$ emulsion and the microcapsules were estimated.

Here, the magnification times of the objective lens is 20 .

\subsubsection{FTIR Analysis}

In order to confirm whether camellia oil is microencapsulated with chitosan or not, the microcapsules were analyzed with FTIR (FTIR-800PC, Shimazu Seisakusho, Ind., Co., Kyoto, Japan).

\subsubsection{Adhesion of Microcapsules on Human Hair}

It was observed with the optical microscope (BH-2VMA: Olympus, Co., Ltd, Tokyo, Japan) how the microcapsules adhered on the surface of human hair.

Namely, human hair was immersed in the microcapsules slurry for $5 \mathrm{~min}$ at room temperature. After this, human hair was dried over night at room temperature and observed with the optical microscope. Then, human hair was dried with blower for a few minutes and observed with the optical microscope. From these photographs, adhesion feature of the microcapsules on human hair was discussed.

\section{Results and Discussion}

\subsection{Observation of Oil Droplets before and after Microencapsulation}

In order to investigate whether the oil droplets were microencapsulated with chitosan due to heterocoagulation or not, first the $(\mathrm{O} / \mathrm{W})$ emulsion before and after microencapsulation was observed.

Figure 2 shows the diameter distributions of oil droplets in the $(\mathrm{O} / \mathrm{W})$ emulsion which was formed by stirring with the rotor stator homogenizer under the experimental conditions such as $\mathrm{Nr}=5000 \mathrm{rpm}, \mathrm{t}=5 \mathrm{~min}$ and $\mathrm{T}=40^{\circ} \mathrm{C}$.

The oil droplets with the mean diameter of $3.9 \mu \mathrm{m}$ and the value of $\mathrm{CV}=0.11$ were formed, where $\mathrm{CV}$ is the coefficient of variation and defined as the ratio 
$(\sigma / \mathrm{dp})$ of the standard deviation $(\sigma)$ of diameter distribution to the mean diameter (dp).

The smaller the CV values are, the more uniform the diameters become.

Also, Figure 3 shows the optical microscopic photograph of the oil droplets in the $(\mathrm{O} / \mathrm{W})$ emulsion before microencapsulation.

The mean diameter and the $\mathrm{CV}$ value were $3.9 \mu \mathrm{m}$ and 0.11 , respectively. Furthermore, the $(\mathrm{O} / \mathrm{W})$ emulsion formed was found to be extremely stable, because the diameters of oil droplets were kept almost constant for $24 \mathrm{~h}$. This stability of the $(\mathrm{O} / \mathrm{W})$ emulsion may be due to the repulsive force based on carboxyl group.

Figure 4 shows the optical microscopic photographs of the oil droplets after microencapsulation. The mean diameter and the $\mathrm{CV}$ value of the oil droplets after a few days were $\mathrm{dp}=3.9 \mu \mathrm{m}$ and $\mathrm{CV}=0.11$, respectively and those of the oil droplets after a week were $\mathrm{dp}=4.0 \mu \mathrm{m}$ and $\mathrm{CV}=0.12$, respectively. From this result, it was found that the $(\mathrm{O} / \mathrm{W})$ emulsion was kept almost unchanged. Accordingly, it may be imagined that microencapsulation of oil droplets was satisfactorily performed.

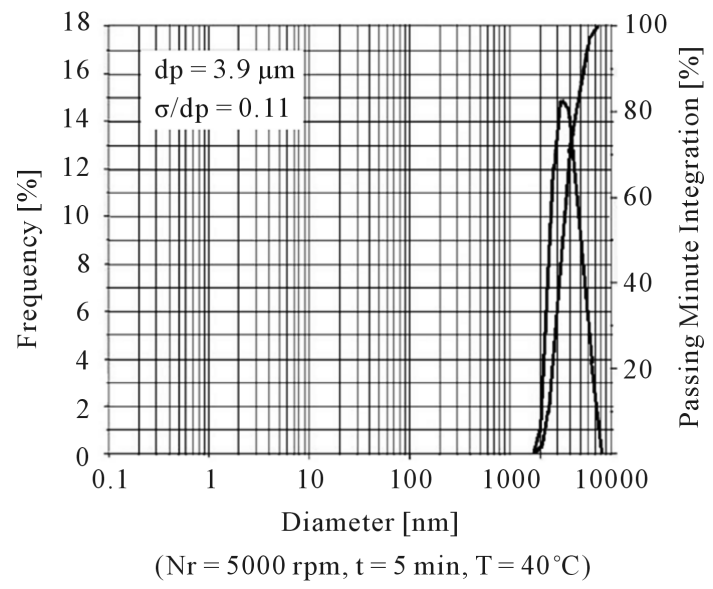

Figure 2. Diameter distribution of oil droplets.

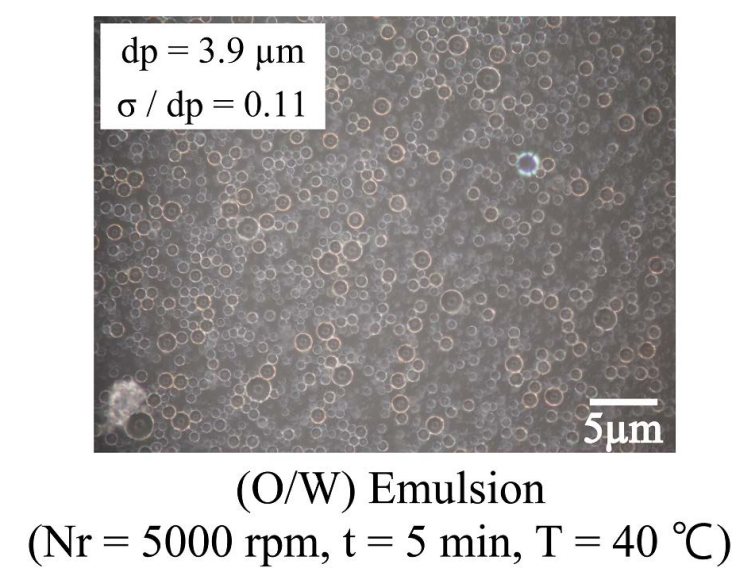

Figure 3. Optical microscopic photograph of oil droplets before microencapsulation. 


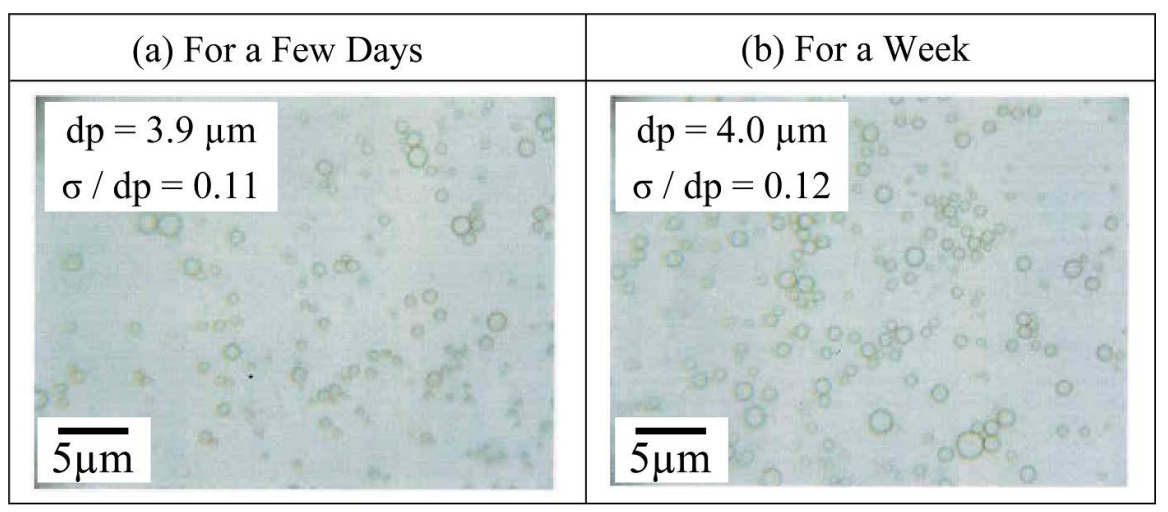

$$
\left(\mathrm{Nr}=5000 \mathrm{rpm}, \mathrm{t}=5 \mathrm{~min}, \mathrm{~T}=40^{\circ} \mathrm{C}\right)
$$

Figure 4. Optical microscopic photographs of oil droplets after microencapsulation.

\section{2. -Potential of Oil Droplets before and after Microencapsulation}

In this study, as it was tried to microencapsulate camellia oil due to heterocoagulation between $\mathrm{OA}$ with carboxyl group and chitosan of polycation, the $\zeta$-potentials of oil droplets before and after microencapsulation were measured. Figure 5 shows the $\zeta$-potentials of oil droplets measured before and after microencapsulation. The $\zeta$-potentials of oil droplets before and after microencapsulation are $-54.6 \mathrm{mV}$ and $59.6 \mathrm{mV}$, respectively. From these results, it may be capable of being thought that the oil droplets were miroencapsulated with chitosan due to heterocoagulation between OA and chitosan. Furthermore, as the oil droplets are microencapsulated with chitosan positively charged, adhesion of these oil droplets onto the negatively charged human hair will be promoted.

\subsection{FTIR Analysis}

In order to analyze the chemical composition on the surface of oil droplets, the results of FTIR analysis for chitosan and the oil droplets after microencapsulation are shown in Figure 6. As the adsorption peaks at $=1500 \mathrm{~cm}^{-1}$ and 3400 $\mathrm{cm}^{-1}$ are due to $\mathrm{NH}_{2}$ of chitosan, the oil droplets are found to be microencapsulated with chitosan. From the results obtained above, it is confirmed that the microcapsules containing camellia oil could be prepared according to the formation mechanism presented in this study, which was shown in Figure 7. Namely, as the oil droplets made from $\mathrm{CO}$ and $\mathrm{OA}$ were charged negatively, the microcapsule shell was formed with heterocoagulation between OA and chitosan of polycation.

\subsection{Dependence of Diameters of Oil Droplets and Microcapsules on Revolution Velocity}

Here, when the microcapsules are going to be applied as a spray type hair dressing material, the diameters of microcapsules are very important to use them efficiently. 
(a) Oil Droplets Before Microencapsulation

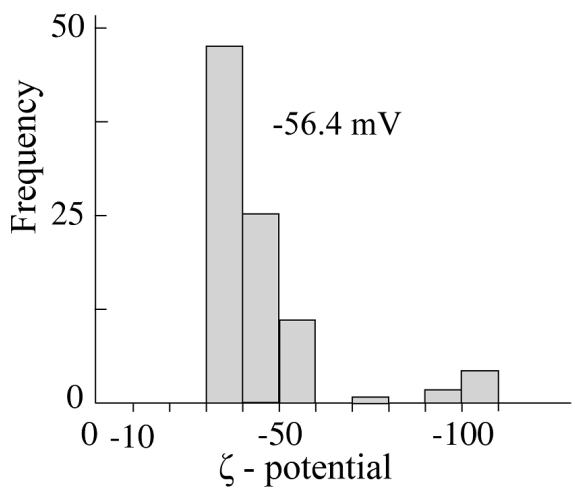

(b) Oil Droplets Aftre Microencapsulation

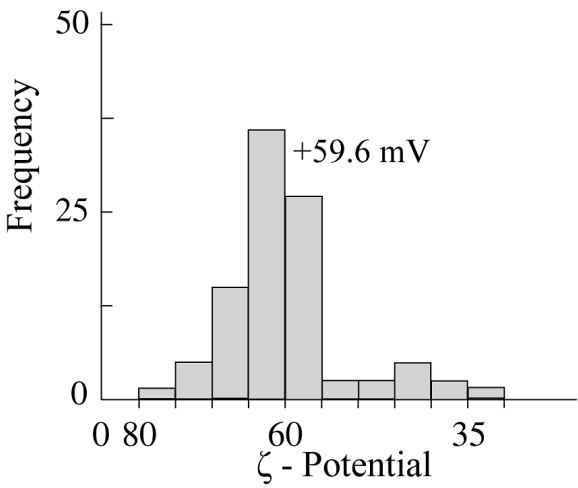

Figure 5. $\zeta$-potential of oil droplets before and after microencapsulation.

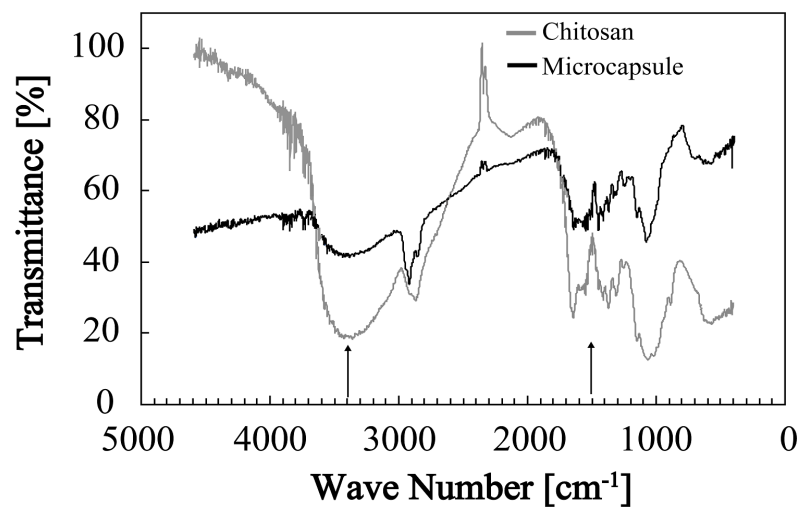

Figure 6. FTIR analysis of microcapsule and chitosan.

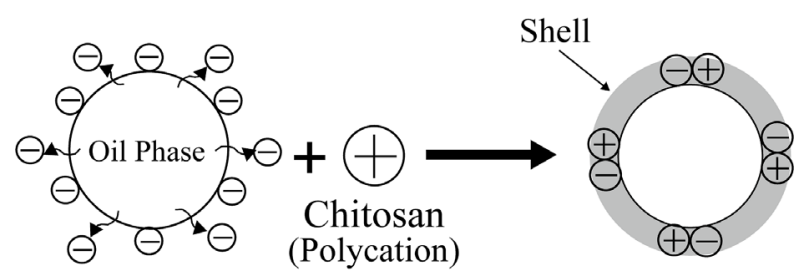

Oil Droplt

Microcapsule

$\left[\begin{array}{c}\text { Camellia Oil } \\ + \\ \text { Oleic Acid }\end{array}\right]$

Figure 7. Formation mechanism of microcapsules.

So, in order to investigate the controllable region of the diameters of the microcapsules, the mean diameters of the microcapsules were measured by changing the revolution velocity to form the $(\mathrm{O} / \mathrm{W})$ emulsion.

On preparing the microcapsules with the heterocoagulation method under the experimental conditions adopted in this study, the diameters of the microcapsules approximately equal to those of the oil droplets in the $(\mathrm{O} / \mathrm{W})$ emulsion.

Figure 8 shows the dependence of the mean diameters of the microcapsules on the revolution velocity $(\mathrm{Nr})$ to form the $(\mathrm{O} / \mathrm{W})$ emulsion. 
From Figure 8, the following experimental equation could be obtained.

$$
\mathrm{dp} \sim \mathrm{Nr}^{-1.17}
$$

This dependency agrees well with that $\left(\sim \mathrm{Nr}^{-1.20}\right)$ for the $(\mathrm{O} / \mathrm{W})$ emulsion formed in the disruptive dominant field [25] [26]. Accordingly, the diameters of the microcapsules are able to be controlled using Weber Number $\left(\rho \mathrm{Nr}^{2} \mathrm{di}^{3} / \gamma\right)$ as a criteria, where $\rho$, di, $\gamma$ are the density of the continuous water, the impeller diameter, the interfacial tension, respectively. In this study, the mean diameters of the microcapsules could be changed in the region from $1.5 \mu \mathrm{m}$ to $4.5 \mu \mathrm{m}$ with the revolution velocity.

Also, the CV values for all the microcapsules prepared in this study were in the range from 0.09 to 0.16 . As a result, the diameters of the microcapsules were found to be more uniform.

\subsection{Adhesion of Microcapsules}

It is well known that, as the human hair is negatively charged, the positively charged particles are easily adhered on the surface of human hair. So, it was investigated whether the microcapsules adhered well on the surface of human hair or not.

Figure 9 shows the optical microscopic photographs of human hair on which the microcapsules adhered after drying at room temperature. From these photographs, it was found that the microcapsules adhered well on the surface of human hair.

Also, Figure 10 shows the optical microscopic photographs of microcapsules on the glass plate after drying due to blowing. The microcapsules appeared due to flattening larger than those before blowing as shown in Figure 4, but were found to be stable even after drying.

From these results, it is expected that the microencapsulated camellia oil can be applied as a hair dressing material.

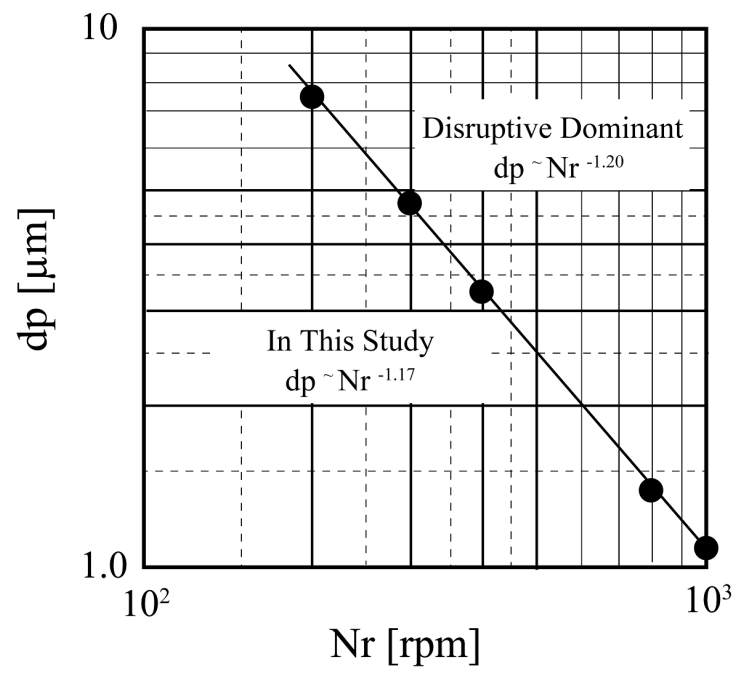

Figure 8. Dependence of mean diameters of oil droplets on revolution velocity. 


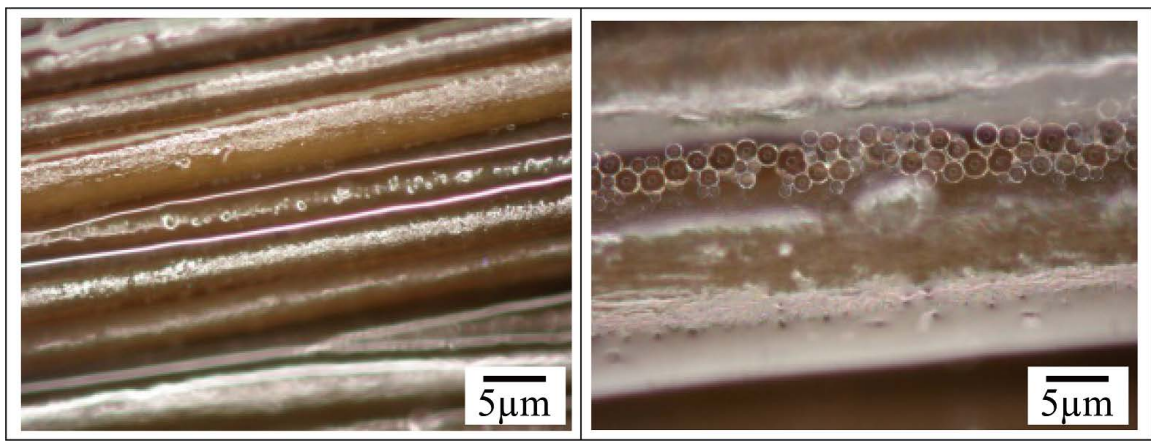

Figure 9. Observation of adsorption of microcapsules.

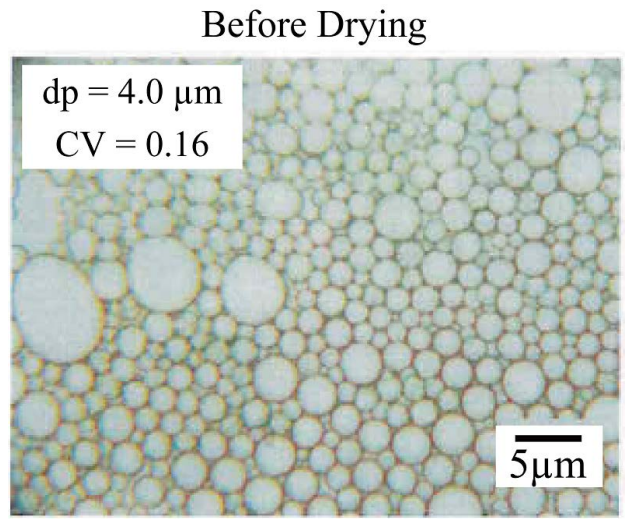

Figure 10. Optical microscopic photograph of microencapsulation after and drying due to blowing.

\section{Conclusions}

It was tried to microencapsulate camellia oil with heterocoagulation between oleic acid and chitosan and it was investigated whether the microcapsules could be applied to the hair dressing material or not. The following fundamental results were obtained.

The microcapsules with the mean diameters in the range from $1.5 \mu \mathrm{m}$ to ca. $4.5 \mu \mathrm{m}$ could be prepared with the formation mechanism presented in this study.

The microcapsules were positively charged in the continuous water and adhered well on the surface of human hair. The microcapsules were kept stably on the human hair before and after drying. In the near future, it will be necessary to investigate the dispersing behavior of microcapsules in the water phase with the various $\mathrm{pH}$ values and the hair dressing effect of the microencapsulated camellia oil and to compare with other dressing materials such as various essential oils.

\section{References}

[1] Kondo, T. (1967) Saishin Maikurokapseruka Gijutsu (Microencapsulation Technique). TES, Tokyo.

[2] Tanaka, M. (2008) Key Point of Preparation of Nano/Microcapsules. Techno System Publishing Co. Ltd., Tokyo. 
[3] Koishi, M., Eto, K. and Higure, H. (2005) (Preparation + Utilization) Microcapsules. Kogyo Chosakai, Tokyo.

[4] Wang, J.M., Zheng, W., Song, Q.W., Zhu, H. and Zhou, Y. (2009) Preparation and Characterization of Natural Fragrant Microcapsules. Journal of Fiber Bioengineering and Informatics, 1, 293-300. https://doi.org/10.3993/jfbi03200907

[5] Lee, H., Jeong, C., Ghafoor, K., Cho, S. and Park, J. (2011) Oral Delivery of Insulin Using Chitosan Capsules Cross Linked with Phytic Acid. Bio-Medical Materials and Engineering, 21, 25-36.

[6] Suthaphot, N., Chulakup, S., Chonsakorn, S. and Mongkholrattanasit, R. (2012) Application of Aroma Therapy on Cotton Fabric by Microcapsules. International Conference: Textiles \& Fashion 2012, Bangkok, 3-4 July 2014.

[7] Satapathy, D., Biswas, D., Behera, B., Sagiri, S.S., Pal, K. and Pramanik, K. (2013) Sunflower-Oil-Based Lecithin Organogelsas Matrices for Controlled Drug Delivery. Journal of Applied Polymer Science, 129, 585-594. https://doi.org/10.1002/app.38498

[8] Hsieha, W.C., Changb, C.P. and Gaoc, Y.L. (2006) Controlled Release Properties of Chitosan Encapsulated Volatile Citronella Oil Microcapsules by Thermal Treatments. Colloids and Surfaces B: Biointerfaces, 53, 209-214.

https://doi.org/10.1016/j.colsurfb.2006.09.008

[9] Iamrungraksa, T. and Charuchinda, S. (2010) Preparation and Characteristics of Galangal Essential Oil/Alginate Microcapsules. Journal of Metals, Materials and Minerals, 20, 89-92.

[10] Soliman, E.A., El-Moghazy, A.Y., Mohy El-Din, M.S. and Massoud, M.A. (2013) Microencapsulation of Essential Oils within Alginate: Formulation and in Vitro Evaluation of Antifungal Activity. Journal of Encapsulation and Adsorption Sciences, 3, 48-55. https://doi.org/10.4236/jeas.2013.31006

[11] Paques, J.P., van der Linden, E., van Rijn, C.J. and Sagis, L.M. (2014) Preparation Methods of Alginate Nanoparticles. Advances in Colloid and Interface Science, 209, 163-171. https://doi.org/10.1016/j.cis.2014.03.009

[12] Belyaeva, E., Valle, D.D., Neufeld, R.J. and Poncelet, D. (2004) New Approach to the Formulation of Hydrogel Beads Byemulsi \& Cation/Thermal Gelation Using a Static Mixer. Chemical Engineering Science, 59, 2913-2920. https://doi.org/10.1016/j.ces.2004.04.010

[13] Wang, A., Tao, C., Cui, Y., Duan, L., Yang, Y. and Li, J. (2009) Assembly of Environmental Sensitive Microcapsules of PNIPAAm and Alginate Acidand Their Application in Drug Release. Journal of Colloid and Interface Science, 332, 271-279. https://doi.org/10.1016/j.jcis.2008.12.032

[14] Katoh, K., Yoshimura, H. and Fujita, H. (2005) Preparation of Porous Matrices of Natural Polymer Using Microcapsules. http://www.aichi-inst.jp/owari/research/report/owari_2005_08.pdf

[15] Tian, K., Xie, C. and Xia, X. (2013) Chitosan/Alginate Multilayer Film for Controlled Release of IDM on Cu/LDPE Composite Intrauterine Devices. Colloids and Surfaces B: Biointerfaces, 109, 82-89. https://doi.org/10.1016/j.colsurfb.2013.03.036

[16] Su, J.F., Wang, S.B., Zhang, Y.Y. and Huang, Z. (2011) Physicochemical Properties and Mechanical Characters of Methanol-Modified Melamine-Formaldehyde (MMF) Shell MicroPCMS Containing Paraffin. Colloid and Polymer Science, 289, 111-119. https://doi.org/10.1007/s00396-010-2328-1

[17] Yuan, Y., Zhang, N., Tao, W., Cao, X. and He, Y. (2014) Fatty Acids as Phase Change Materials: A Review. Renewable and Sustainable Energy, 29, 482-498. 
https://doi.org/10.1016/j.rser.2013.08.107

[18] Yang, Z., Peng, Z., Li, J., Li, S., Kong, L., Li, P. and Wang, Q. (2014) Development and Evaluation of Novel Flavour Microcapsules Containing Vanilla Oil Using Complex Coacervation Approach. Food Chemistry, 145, 272-277. https://doi.org/10.1016/j.foodchem.2013.08.074

[19] Chang, C.P., Leung, T.K., Lin, S.M. and Hsu, C.C. (2006) Release Properties on Gelatin-Gum Arabic Microcapsules Containing Camphor Oil with Added Polystyrene. Colloids and Surfaces B: Biointerfaces, 50, 136-140. https://doi.org/10.1016/j.colsurfb.2006.04.008

[20] Soottitantawat, A., Bigeard, F., Yoshii, H., Furuta, T., Ohkawara, M. and Linko, P. (2005) Influence of Emulsion and Powder Size on the Stability of Encapsulated d-Limonene by Spray Drying. Innovative Food Science and Emerging Technologies, 6, 107-114. https://doi.org/10.1016/j.ifset.2004.09.003

[21] Polavarapu, S., Oliver, C.M., Ajlouni, S. and Augustin, M.A. (2012) Impact of Extra Virgin Olive Oil and Ethylenediaminetetraacetic Acid (EDTA) on the Oxidative Stability of Fish Oil Emulsions and Spray-Dried Microcapsules Stabilized by Sugar Beet Pectin. Journal of Agricultural and Food Chemistry, 60, 444-450. https://doi.org/10.1021/jf2034785

[22] Gharsallaoui, A., Saurel, R., Chambin, O., Cases, E., Voilley, A. and Cayot, P. (2010) Utilisation of Pectin Coating to Enhance Spray-Dry Stability of Pea Protein-Stabilised Oil-in-Water Emulsions. Food Chemistry, 122, 447-454. https://doi.org/10.1016/j.foodchem.2009.04.017

[23] Taguchi, Y., Ono, F. and Tanaka, M. (2013) Preparation of Microcapsules Containing $\beta$-Carotene with Thermo Sensitive Curdlan by Utilizing Reverse Dispersion. Pharmaceutic, 5, 609-620. https://doi.org/10.3390/pharmaceutics5040609

[24] Jung, E., Lee, J., Back, J., Jung, K., Lee, T., Huh, S., Kim, S., Koh, J., and Park, D. (2007) Effect of Camellia japonica Oil on Human Type I Procollagen Production and Skin Barrier Function. Journal of Ethnopharmacology, 112, 127-131. https://doi.org/10.1016/j.jep.2007.02.012

[25] Tanaka, M. and Tanaka, M. (1989) Effect of Sudden Reduction of Impeller Speed on Particle Size Distribution in Suspension Polymerization of Styrene. Journal of Chemical Engineering of Japan, 22, 559-561. https://doi.org/10.1252/jcej.22.559

[26] Hosogai, K. and Tanaka, M. (1992) Study of Suspension Polymerization of Styrene with a Circular Loop Reactor. Polymer Engineering Science, 32, 431-437. https://doi.org/10.1002/pen.760320608 